\title{
CONSIDERACIONES SOBRE EL DELITO DE LAVADO DE DINERO, EL SECRETO BANCARIO Y SU ALZAMIENTO
}

\author{
Hernán O. Silva Silva \\ Profesor de Ciencias Penales y Criminología \\ Escuela de Derecho \\ Universidad San Sebastián
}

\section{INTRODUCCIÓN}

1. La cuestión del tráfico ilegal de drogas es de gran actualidad, tanto de índole nacional como internacional. Como dice el Licenciado en Derecho graduado en el Instituto de Criminología de la Universidad Complutense de Madrid, España, Juan Espinazo García, "La Droga: Problema de vigencia universal". En efecto, en el presente, prácticamente en todos los países del mundo se abocan a los problemas derivados del narcotráfico, de los narcotraficantes, del narcodólar, de los estupefacientes, del lavado de dinero, del narcolavado y preocupa a un número importante de organismos, tanto gubernamentales como no gubernamentales. Las drogas, los tóxicos y los sicotrópicos se consideran como uno de los males del siglo, y que azota a la humanidad produciendo graves trastornos tanto físicos como mentales, irreversibles al ser humano. El consumo de las drogas produce a corto tiempo un hábito incontrolable, una tóxico-dependencia, tolerancia y perjuicios a la salud individual, a la salud pública y para la sociedad entera.

2. Se han realizado varias reuniones Cumbres sobre Drogas, por ejemplo, en San Antonio Texas, el 26 y 27 de febrero de 1992, concurriendo los Presidentes de Bolivia, Colombia, Ecuador, Méjico, Perú y los Estados Unidos de Norteamérica, y el Ministro de Relaciones Exteriores de Venezuela. Otra reunión importante, fue la de las Naciones Unidas, la Conferencia Internacional sobre la Prevención y Represión del Blanqueo de Dinero y el Empleo del Producto del Delito, un enfoque mundial, en Courmayeur, Italia, del 18 al 20 de junio de 1994. En las sesiones correspondientes se formularon declaraciones, y entre otras la necesidad de la cooperación internacional contra las drogas, los cultivos con fines ilícitos, la producción, el tráfico y las redes ilegales de distribución de drogas, el lavado de dinero, el comiso y decomiso de los bienes y, en general, estrategias para el control de las drogas y represión y prevención del lavado de dinero.

3. Profunda conmoción causa a todo nivel, no sólo la ingesta masiva del alcohol, que es denominada "droga social", sino que igualmente el consumo y tráfico de marihuana (Cannabismo), cocaína (Cocainismo) en sus diversas formas, morfina (Morfinismo ), heroína ( Heroinismo ), opio (Opioismo ), tranquilizantes, anfetaminas, alucinógenos, barbitúricos, etc. y que producen adicción. Lo inquietante es que el empleo de las drogas que empieza en forma aislada y esporádica, se transforma en un corto lapso de tiempo en una drogomanía y lo que a la vez trae aparejado, como consecuencia lamentable, la dependencia física, biológica u orgánica y la psíquica o emocional de la persona, o ambas. En otras palabras, la toxicofilia, la fármacodependencia y como resultado final, un proceso de destrucción del ser humano y su muerte. 
4. Además, hay que destacar, que la droga en el presente es de consumo habitual y reiterado en todos los niveles de la sociedad, en los hombres, en las mujeres y desgraciadamente se ha detectado en nuestro país y en el extranjero un aumento de la drogadicción en la juventud y en los menores de edad, atacándose día a día no sólo su salud individual sino que la salud pública.

5. Al margen del uso de la droga se ha generado su tráfico ilícito con incrementos económicos gigantescos, particularmente en los últimos 20 años aproximadamente, formándose empresas de narco o cocadólar, los carteles ( los de Medellín y Cali ), y las mafias, en los denominados países productores o proveedores de tales sustancias, especialmente en los Estados Unidos de Norteamérica, Italia, Francia, China, Hong Kong, Colombia, Perú, Bolivia, Ecuador, Panamá, Jamaica, Chipre, Macao, Honduras, Singapur, etc. La literatura moderna nos señala una nueva forma de gobierno con una estrecha vinculación entre las drogas y el dinero, denominada "Narcocracia"

6. Hay que considerar que las operaciones de venta de la droga, se hacen siempre con dinero efectivo, siendo la moneda comúnmente empleada el dólar, y en billetes de bajo monto o valor, produciéndose inmensas cantidades o volúmenes de ellos, circulando y formando parte de la economía de los países respectivos, y es necesario su blanqueamiento por los traficantes o terceros que se han concertado, para ingresarlos a otros capitales que se estiman lícitos llegando entre sí a confundirse.

7. Edgar Saavedera Rojas y Rosa del Olmo, en su Obra, "La Política Criminal del Narcotráfico, como consecuencia de la Convención de Viena de 1988", Editorial Temis S.A., Bogotá Colombia, año 1991, pág. 37, citado por Raúl Peña Cabrera, al respecto consigna, "Debido a que los billetes de denominación de cien dólares, pesan tres veces más que la droga que genera esa cantidad ( 450 billetes pesa una libra aproximadamente) hace, que las denominaciones de 10 ó 20 dólares sean las preferidas por los narcotraficantes que quieren lavar dinero. Estos billetes de baja denominación pesan 15 a 30 veces su peso equivalente en cocaína".

8. Los ingresos ilegales denominados "platas o dineros negros", algunos hablan de capitales grises, son destinados en la adquisición de bienes de cualquier naturaleza, tales como muebles, inmuebles, bonos, acciones, intangibles, etc., o aportados a empresas que funcionan legalmente. En ciertos casos, tales dineros son depositados en las cuentas corrientes bancarias, en uno o varios países y traspasados electrónicamente de banco a banco o financieras, u organismos similares, por medio de computadoras en pocos segundos. Estas operaciones están amparadas por el secreto, reserva bancaria y tributaria, lo que dificulta su origen, el destino y prácticamente los que llegan a fusionarse con los capitales lícitos. Sin perjuicio de lo anterior, se observa que en las recientes legislaciones modernas se permite el acceso a las cuentas corrientes bancarias y a la documentación tributaria, dejando, por lo tanto, sin efecto dicha reserva en la investigación del delito de lavado de dinero, como ocurre, entre otros países, en Suiza, Holanda, Francia, Perú, Estados Unidos de Norteamérica, etc. En cambio, se mantiene en forma absoluta, formando los llamados "Paraísos Financieros o Tributarios", en las Islas Caimán, las Bermudas, las Bahamas, los Emiratos Arabes, Andorra, Hungría, Gibraltar, Antillas Holandesas, Singapur, etc.

9. Nos permitimos dejar establecido en estos lineamientos, que en el Derecho Comparado y en la doctrina no hay un acuerdo unánime en la denominación de estos ingresos ilegales, provenientes del narcotráfico y por lo demás esta es sólo una de sus 
fuentes generatorias, como lo examinaremos. Si bien es cierto, la expresión Lavado de Dinero (en inglés Money Laundering, en alemán Geldwaschel), es la más conocida y gráfica, pues está indicando que el dinero o platas negras, al lavarse se blanquean y tienen la apariencia de fondos lícitos y así ingresan al mercado de capitales, otros prefieren el término de "Lavado o Blanqueo de Capitales", Reciclaje de Dinero, en Italia Reciclaggio del Denaro, o de Encubrimiento Financiero o Impropio. También se emplea la denominación de blanqueado de dinero (en Francia Blanchiment de L'Argent, Branqueamento). Un grupo de autores propicia rotular este delito "Lavado de Activos relacionados con el Tráfico llícito de Drogas".

10. Por último, desde el punto de vista histórico, existe una abundante literatura y en varios de los textos se argumenta que los primeros capitales blanqueados, lo habrían sido en Estados Unidos de Norteamérica, en la época de las gángsters y de la Ley Seca. Otros precisan que se habría originado con posterioridad a la Segunda Guerra Mundial. Fernando García, en su estudio "Lavado de Dinero y Narcotráfico. La Droga como Negocio". Documentos docentes. Material de trabajo del alumno. Universidad Central, Facultad de Ciencias Económicas y Administrativas, 1996 página 7, al respecto comenta: "Cuentan que en el Chicago de la década de los años 20, un grupo de gángster con negocios en el alcohol, el juego, la prostitución y otras actividades ilícitas, compraron una cadena de lavanderías. Al final de cada día, a las ganancias provenientes de la lavandería, agregaban utilidades provenientes de los otros negocios, las que quedaban "justificadas" como obtenidas en actividades legítimas". Más adelante este mismo autor agrega "De este modo, es lavado de dinero el que efectúa el ladrón que vende lo robado, pero también el realizado durante la Segunda Guerra Mundial por Alemania e Italia, que vendieron a Suiza oro obtenido en los países invadidos. Sólo Alemania, durante ese período vendió más de 1600 millones de francos, esto es, diez veces más que sus reservas oficiales de ese metal. Es decir, del blanqueo de capitales provenientes de actividades ilícitas como hecho económico y social significativo, tenemos noticias desde hace al menos 50 años. Sin embargo, como fenómeno criminal surge sólo recientemente. $\mathrm{O}$ lo que es lo mismo, a nivel internacional sólo en los últimos años aparece definido como conducta delictiva". (Fernando García, ob, cit., pág. 7)

11. Atinente a esta materia Elías Neuman, añade "Con los llamados narcodólares el negocio se extiende considerablemente, pues en la actualidad, después del de venta de armas, el de las drogas es la industria más redituable del planeta. Además, el mundo de la tecnología ha creado un movimiento vertiginoso en las comunicaciones y los servicios se han puesto a la par. Hoy no se requieren firmas para el traspaso de grandes fortunas. Para eso está el fax, y no es preciso que la moneda esté puesta en la ventanilla de un banco, al instante, para formalizar la operación". (Elías Neuman, La Legalización de las Drogas, Ediciones Depalma, Buenos Aires, Argentina, 1991, pág. 45).

\section{GENERALIDADES SOBRE EL LAVADO DE DINERO}

1. Conforme a antecedentes obtenidos del boletín N²67-11 del año 1991 de la Cámara de Diputados de Chile, se infiere que "El Instituto Saint Gall, de Suiza, estimó que el comercio mundial de estupefacientes movilizó 900.000 millones de dólares en 1988 y crece a un ritmo de US\$ 100.000 millones por año. Ese organismo especializado en el estudio del tráfico de narcotráfico sospecha que un tercio de esas cifras (US\$ 
Revista de Derecho - Universidad Católica del Norte - Sede Coquimbo - 1998

300.000 millones), corresponde a los beneficios obtenidos por los barones de la droga de América Latina con sus exportaciones clandestinas de cocaína al mercado norteamericano ",

2. En Chile, de acuerdo a informaciones, especialmente periodísticas, se estima que se lavan importantes sumas de dinero, en diversas actividades comerciales e industriales, en varias regiones del país, pero que por tratarse de un asunto del todo delicado y complejo preferimos en este trabajo, sólo hacer esta breve enunciación.

3. La Ley 19.366, publicada en D.O. del 30 de enero de 1995 "SANCIONA EL TRAFICO ILICITO DE ESTUPEFACIENTES Y SUSTANCIAS SICOTROPICAS, DICTA Y MODIFICA DIVERSAS DISPOSICIONES LEGALES Y DEROGA LA LEY 18.403", tipifica en su artículo 12, el llamado delito del "lavado de dinero", y en el artículo 16 letra d), según la modificación de la Ley 19.393, de 22 de junio del mismo año, se autoriza el levantamiento del secreto bancario, previo cumplimiento de ciertos requisitos que analizaremos. Por otra parte, una de las primeras fases de la comprobación del hecho ilícito corresponde, de la manera que se establece, únicamente al Consejo de Defensa del Estado y posteriormente, en la otra etapa, a los Tribunales Ordinarios de Justicia, con competencia en lo criminal.

4. Antes de las explicaciones específicas, creemos que debemos, a lo menos, indicar algunas generalidades sobre el lavado de dinero, también hay que considerar que esta innovación que hace la Ley de Drogas nacional, no es más que el complemento y cumplimiento de normativas internacionales que contemplan esta infracción y las cuales han sido promulgadas y ratificadas por nuestro país, particularmente en la "Convención de las Naciones Unidas contra el tráfico ilícito de estupefacientes y sustancias psicotrópicas", del 10 de diciembre de 1988, según Decreto Supremo № 543 , publicado en el Diario Oficial del 20 de agosto de 1990.

5. En el Proyecto de Ley, que envió el ejecutivo el 6 de abril de 1992, a la Honorable Cámara de Diputados, en el párrafo pertinente, anota al respecto: "No escapará al alto criterio de esta Honorable Cámara que la principal motivación de las organizaciones delictivas dedicadas al tráfico ilegal de estupefacientes lo constituye el interés económico, la obtención de ganancias. Para desalentar tal propósito, al igual que en la mayoría de las naciones desarrolladas y no pocas naciones americanas, propone sancionar las conductas que tiene por objeto ocultar o encubrir el origen ilícito de los recursos que genera el tráfico ilegal de los estupefacientes".

6. La abogada Consejera del Consejo de Defensa del Estado, Clara Leonora Szczaranski C., en su interesante artículo "Apuntes introductivos a la Ley № 19.366 , reflexiones sobre el consumo de drogas y pauta de análisis del delito de lavado de dinero", publicado en la Gaceta Jurídica № 179, año 1995, pág. 15, nos dice, "Pero, sin duda, entre sus más importantes innovaciones la nueva ley contempla la sanción del conjunto de conductas constitutivas del denominado "lavado de dinero", vale decir, las que tienen por objeto usar, en cualquier modo, ocultando o encubriendo su origen ilícito, los recursos que generan los delitos de narcotráfico. Los agentes de estos delitos, en su nivel más desarrollado, pretenden y obtienen la integración de sus enormes beneficios ilícitos en el flujo económico legal de una Nación. (Más de US\$29.000 millones sólo en U.S.A. en 1993 y sólo por venta de cocaína, ejemplo repetido, pero esclarecedor). Dichos agentes constituyen organizaciones delictivas para las cuales la "división" - "repartición", y el "lavado" es esencial, estratégica, dotando a esta actividad de 
recursos humanos, financieros y técnicos calificados a fin de ir logrando la necesaria incorporación al flujo económico normal referido más allá de las barreras que logran oponer los Estados; para ello, invierten ingentes sumas en protección, corrupción, estudios técnicos, etc. Se puede afirmar que se trata de acciones delictivas casi siempre "inteligentes y complejas".

\section{CONCEPTOS DEL LAVADO DE DINERO.}

1. Para Raúl Tomás Escobar: "El "lavado de dinero", es el procedimiento subrepticio, clandestino y espurio mediante el cual los fondos o ganancias procedentes de actividades ilícitas (armamento, prostitución, trata de blancas, delitos comunes, económicos, políticos y conexos, contrabando, evasión tributaria, narcotráfico), son reciclados al circuito normal de capitales o bienes y luego usufructuados mediante ardides tan heterogéneos como tácitamente hábiles". (Raúl Tomás Escobar, "El Crimen de la Droga", Buenos Aires, Argentina, 1992, pág. 381).

2. Según Roberto J. Bulit G. En su trabajo titulado El Lavado de Dinero en la Legislación y Jurisprudencia Americana, dice "El lavado de dinero es la acción que tiene como finalidad la conversión del producto monetario o de las utilidades de una actividad ilícita en activos -financieros o no- que muestren un origen legítimo". (Revista Jurídica Argentina, La Ley N 103, Buenos Aires, 30 de abril de 1991, tomo C, pág. 1109).

3. Gabriel Adriasola: "En efecto, el lavado o blanqueo comporta el ocultamiento de fondos de origen delictivo y su posterior reingreso al mercado dinerario con apariencia lícita. En verdad resulta de disfrazar las ganancias ilícitas, de "limpiarlas" -de ahí su nombre- mediante operaciones empresariales e inversiones diversas. De esta manera, el "lavado" de dinero sucio no solamente compromete al proveniente del narcotráfico, sino de cualquier actividad delictiva de crimen organizado, a saber, la trata de blancas, secuestros terroristas, delitos ecológicos, defraudación tributaria". (Gabriel Adriasola, El Nuevo Derecho sobre Tóxicos y el Lavado de Dinero de la Droga, Fundación de Cultura Universitaria, Montevideo, Uruguay, 1994, pág. 63).

4. El Act Australiana de 1997, lo define como "La participación directa o indirecta en transacciones que involucren dinero $u$ otros bienes provenientes de un delito, así como ocultar, receptar, poseer, enajenar o introducir al país cualquier clase de dinero o propiedades provenientes de un delito",

5. Para la Legislación Inglesa de 1986, es "El convertir o participar de cualquier modo en ayudar a que se controlen o retengan las ganancias del tráfico de drogas, resguardar dichos fondos o facilitar su inversión".

6. La Ley Suiza de 1985, anota que es "La realización de un acto susceptible de frustrar la verificación de la proveniencia, el hallazgo o la confiscación de valores patrimoniales sabiendo o debiendo presumir que provienen de un crimen".

7. Fernando García Díaz, lo conceptualiza "En términos generales, podemos señalar que se puede entender como lavado de dinero o blanqueo de capitales, cualquier procedimiento mediante el cual dinero o bienes procedentes de actividades ilícitas son incorporadas al circuito normal de capitales y bienes y a menudo legitimados como provenientes de actividades legítimas". (Fernando García, ob. cit. pág. 7). 
8. En el boletín de la Cámara de Diputados a que ya hemos hecho referencia, $N^{\circ}$ 267-11 sobre el lavado de dinero, apunta, "Esta operación, que puede revestir múltiples formas, permite hacer pasar, convertir, transformar o transferir dineros, cosas o ganancias provenientes del narcotráfico a empresas, negocios, depósitos o cuentas corrientes aparentemente legales".

9. Para nosotros y ensayando una definición, concluimos que el lavado o blanqueo de dinero en sentido restringido, y para los efectos exclusivamente de la Ley de Drogas, "Consiste en convertir, transferir, invertir, ocultar, en cualquier otra forma similar, los fondos obtenidos en forma ilícita provenientes del tráfico de drogas y poder posteriormente ser incorporados a capitales obtenidos legalmente".

\section{Comentario}

1. De las definiciones anotadas arriba y como se desarrollará en otros apartados, la denominación de lavado de dinero, se destina en general por la mayoría de las leyes o códigos a los ingresos ilegales provenientes del negocio de la droga. Esto ocurre, por ejemplo, en la legislación peruana, ecuatoriana, panameña, etc., las que serán revisadas en otros capítulos.

2. Conforme a la doctrina penal en materia de blanqueo de capitales, término que nosotros usaremos más adelante como similar o análogo al lavado de dinero, se refiere a cualquier bien, dinero, beneficio o ganancia económica obtenida en forma ilícita y entre tales modalidades los provenientes del comercio ilegal de drogas y cuyos fondos se destinan a sociedades o negocios legalmente constituidos. De aquí precisamente emana el nombre del delito, pues el dinero negro se lava, limpia o blanquea para que tengan las apariencias de ser capitales lícitos, como ya lo enunciamos.

3. Otras fuentes de ingresos ilegales son los provenientes de la perpetración de infracciones tributarias, evasión de impuestos, contrabando, de los delitos ecológicos, de la prostitución internacional, venta de armas, secuestro, terrorismo, trata de blancas, tráfico de menores, de niños, etc, y en general de cualquier delito organizado que produzca ingresos o dineros.

\section{EL SECRETO BANCARIO Y EL DELITO DE LAVADO DE DINERO}

\section{EL LAVADO DE DINERO EN LA LEGISLACION NACIONAL}

1. El artículo 12 de la Ley 19.366, describe por primera vez, en nuestra Legislación Nacional el delito de "lavado de dinero" como sigue: "El que, a sabiendas que determinados bienes, valores, dineros, utilidad, provecho o beneficio se han obtenido o provienen de la perpetración, en Chile o en el extranjero, de hechos constitutivos de alguno de los delitos contemplados en esta ley, participe o colabore en su uso, aprovechamiento o destino, será castigado con presidio mayor en sus grados mínimo a medio y multa de doscientas a mil unidades tributarias mensuales. Se entiende por uso, aprovechamiento o destino de los bienes aludidos precedentemente todo acto, cualquiera que sea su naturaleza jurídica, que importe o haya importado tenencia, posesión o dominio de los mismos, sea de manera directa o indirecta, originaria, simulada, oculta o encubierta". 
2. Indicaremos que el autor o sujeto activo del delito y de acuerdo al precepto transcrito puede ser cualquier persona ( sujeto simple o común ) y que un elemento del tipo penal es el requisito "a sabiendas", lo que se materializa en la culpabilidad o elemento subjetivo de la infracción, en otras palabras, el dolo, que en nuestro concepto, tendría que ser "dolo directo" por la forma en que está redactado dicho precepto. No descartamos la posibilidad de la existencia del dolo eventual, el que ha sido reconocido ampliamente por la doctrina y jurisprudencia nacional. El adverbio "a sabiendas", que es igualmente empleado en el Derecho extranjero o la expresión "debiendo saber", "o que hubiere sospechado", en esta materia, significa el conocimiento de la ilicitud y la voluntariedad en la conversión o inversión de los capitales. En otras palabras, que el agente sabe o conoce el origen de los fondos, valores o capitales, etc. y que éste es precisamente del tráfico ilícito de drogas. Si la persona no tiene este conocimiento, y por lo tanto, estaría actuando de buena fe, no existiría el dolo, o este se habría simplemente eliminado, operando una causal de exculpación.

3. Don Víctor Prado Saldarriaga, analizando este injusto en el Código Penal peruano, puntualiza "A nivel del tipo subjetivo el legislador ha considerado que las conductas incriminadas por el dispositivo legal que se revisa, deben ejecutarse dolosamente. Debiendo comprender el dolo del agente la conciencia y voluntad sobre la procedencia u origen ilegal del bien o ganancia que se convierta, transfiera u oculte. Es más, la ley incluso declara como suficiente para la tipicidad del hecho, el que el sujeto activo haya sospechado de la ilegalidad de la procedencia de los bienes o ganancias en razón de su posible conexión con el producto del narcotráfico. No obstante, si en el agente concurren subjetivamente ignorancia, error o buena fe al momento de adquirir, transferir o poseer un bien de procedencia criminosa, su comportamiento deviene en atípico y carente de relevancia penal". (Víctor Roberto Prado Saldarriaga. El Delito de Lavado de Dinero, Su tratamiento penal y bancario en el Perú. Doctrina, Convenios Internacionales, Legislación Comparada, Legislación Bancaria, Legislación. Tributaria. Importaciones y Distribuidora Editorial Moreno S.A., Perú, 1994, pág. 69).

4. Este artículo 12 contempla una figura delictiva, con una diversidad de hipótesis o conductas alternativas, como se observa de su simple lectura, bastando para su configuración alguna de ellas y en cualquier forma que se cometa. Al inicio prescribe "el que" pudiendo ser, por lo tanto, cualquier tipo de sujeto, no siendo necesario uno calificado, cualificado o especial. En nuestra legislación, el artículo 12 no señala expresamente para castigar el delito de lavado de dinero, el elemento "el que sin haber tomado parte" en otros ilícitos descritos en la ley 19.366. En la legislación comparada, se preceptúa específicamente que el autor del blanqueo de capitales no tiene que haber intervenido en la comisión o cooperación de otros delitos reprimidos por la ley de drogas.

5. Relativo a la responsabilidad criminal, el artículo 12 manifiesta: "participe o colabore" y habría que estarse para la determinación particular de la conducta a las normas del artículo 15 del Código Penal, en cuanto sea aplicable a este caso, principalmente la autoría directa o material del artículo 15 № 1, parte primera, esto es, "Los que toman parte en la ejecución del hecho sea de una manera inmediata o directa", o en la forma que detalla el artículo 15 № 3 parte primera del mismo ordenamiento, vale decir. "Los que concertados para su ejecución facilitan los medios con que se lleva a efecto el hecho". Igualmente podría darse la calidad de autores inductores del artículo $15 \mathrm{~N}^{\circ} 2$ parte $2^{\circ}$, "Los que inducen directamente a otros a ejecutarlo". 
6. La colaboración se asimila a la autoría, según la redacción del artículo 12 de la Ley, y también requiere la concurrencia del elemento subjetivo, "A sabiendas", pero no significa en nuestro concepto que se elimina de este delito la calidad de cómplices y para tal efecto, debemos remitirnos al artículo 16 del Código Penal, excluyéndose la calidad de autor del artículo 15 y cooperen a la ejecución del hecho por actos anteriores o simultáneos, vinculados al delito mismo de lavado de dinero. Recordemos, aunque sea al pasar, que el artículo 15 del Código Penal, contempla una serie de acciones que técnicamente revisten el carácter de conductas de complicidad, pero que el legislador las eleva a la calidad de autores. Corresponderá en última instancia, en este complejo delito, determinar si estamos frente a una participación de autor o de cómplice, al Juez, ya que dicho precepto anota: "Se consideran autores "y no dice "son autores".

7. Estimamos que lo enunciado en el párrafo anterior es esencial no sólo para determinar la participación punible en el delito de blanqueamiento de dinero sino que también por las consecuencias que ello trae aparejado, atinente al punto en estudio. Si se determina que una persona tiene la calidad de partícipe en el lavado de dinero podrá en su oportunidad procederse al examen de su cuenta corriente bancaria y de las partidas correspondientes para establecer su origen

8. También puede darse la calidad de encubridor en este delito cuando se cumplen los requisitos del artículo 17 del Código Penal, esto es con conocimiento de la acción ilícita, (lavado de dinero) e intervengan con posterioridad a su ejecución en alguna de las cuatro modalidades que allí se detallan, en cuanto sean procedentes según la naturaleza del delito, y no tengan la calidad de autores ni de cómplices.

9. Como lo expresamos más arriba en el artículo 12 que comentamos, emplea el término, "El que", y no cabe la menor duda que estamos frente a una autoría o grado de participación atribuible a una persona natural o física y podemos plantear la interrogante si el delito de lavado de dinero puede ser cometido por una persona jurídica, como puede serlo una sociedad, una corporación, una entidad bancaria, financiera, etc. Recordemos que por regla general, y desde antaño, se sostiene que las personas jurídicas no pueden cometer delitos o ser sujetos activos de los mismos por no tener capacidad delictiva, y que sólo pueden serlo las personas naturales. Sin embargo, una tendencia moderna reconoce en ciertos casos la responsabilidad de las personas jurídicas o colectivas, tales como en materia de responsabilidad laboral, ecológica, etc. Por nuestra parte, estimamos que también puede ser autor ejecutor, una persona jurídica, particularmente un banco, una bolsa de valores. instituciones financieras y otras, siempre que se den los presupuestos del artículo 12, en especial que tengan conocimiento del origen de tales fondos o bienes. Como se expondrá en otros capítulos, en la Legislación peruana y venezolana, se castiga el lavado de dinero cometido por las personas jurídicas, y se le aplican sanciones como su disolución, la clausura, etc.

10. Estos beneficios económicos pueden provenir de la ejecución en Chile o fuera del país, y además el sujeto activo puede tener la calidad de autor propiamente tal de los delitos de tráfico de drogas. En la práctica, creemos que no es incompatible el que una persona sea autor de alguno de los delitos contemplados en la Ley de Drogas, y la misma participación en el lavado de dinero, esto es, autor en ambos tipos penales. Por lo tanto, se generaría un concurso de delitos, y posiblemente el ideal del artículo 75 del Código Penal, ya que un mismo hecho constituye dos o más delitos, imponiéndose la 
pena mayor asignada al delito más grave o el concurso titulado como medial, vale decir, cuando un delito es el medio necesario para cometer otro delito.

11. Desde un ángulo netamente doctrinario también podría pensarse que estamos en presencia de un concurso material de delitos, pues el autor puede ejecutar cualquiera de los delito de la ley de drogas y además lavar el dinero, que serían las utilidades ilegales, y aplicaríamos la normativa del artículo 74 del Código Penal, de la acumulación material de las penas, o en su caso, para la aplicación de la sanción, las normas de la acumulación jurídica preceptuadas en el artículo 509 del Código de Procedimiento Penal.

12. Otro punto importante, es el contemplado en el mismo artículo 12, ya transcrito, al manifestar lo que debe entenderse sobre el uso, aprovechamiento o destino de los bienes, y consiste en todo acto "cualquiera que sea su naturaleza jurídica, que importe o haya importado tenencia, posesión o dominio de los mismos, de una manera directa o indirecta, originaria, simulada, oculta o encubierta". Más que una definición, estamos en presencia de una presunción simplemente legal y de un contenido amplio que recuerda por su estructura, a las normas penales en blanco.

13. La construcción dogmática del artículo 12, al describir los tipos penales y la presunción posterior, son bastante amplias, tanto el uno como el otro. En cuanto al delito mismo, las conductas típicas punibles son vagas e imprecisas y algunas reiterativas, lo que estaría atentando estrictamente contra el principio de la tipicidad, que es una de las bases fundamentales del Derecho Penal moderno. Pensamos, eso sí, que el legislador ha dado una nueva herramienta de lucha y ha querido abarcar un número ilimitado de acciones injustas, para que estas no queden impunes, dada la gravedad que reviste a la fecha el lavado de dinero y los ingresos gigantescos de millones de dólares anuales, como se ha reseñado precedentemente.

14. Más adelante, el artículo 13 de la Ley, se refiere a una norma adjetiva, en el sentido que el proceso penal por el delito de lavado de dinero, sólo puede ser iniciado por la vía judicial y por un organismo especial, que es el Consejo de Defensa del Estado, por medio de querella o denuncia, pero una vez que se haya puesto término a la llamada investigación extrajudicial, previa o administrativa. Dicho precepto reza "Los juicios criminales por los delitos penados en el artículo anterior, sólo podrán ser iniciados por querella o denuncia del Consejo de Defensa del Estado, una vez concluida la investigación preliminar a que se alude en los artículos siguientes". Luego, esta primera fase queda entregado a un organismo ajeno al Poder Judicial, el que tiene según el decir de algunos, el monopolio de la acción penal. Se insistió en las sesiones legislativas pertinentes que esta instancia no tiene el carácter de judicial sino que meramente administrativo. En el proyecto esta función se le entregaba al Banco Central de Chile y posteriormente se resolvió que el organismo adecuado era el referido Consejo.

15. Al respecto, en la sesión $N^{\circ} 57$ del 30 de marzo de 1993, de la Cámara de Diputados, página 5169, y en relación con el boletín 653-07-2, se dejó constancia, "La comisión no obstante ser partidaria de la conveniencia de que exista una investigación preliminar, centró su debate en el organismo encargado de llevarla a cabo y, es así como, no estimó pertinente que se le asignara esta atribución al Banco Central de Chile toda vez que se aparta de su función fundamental que tiene por objeto velar por la estabilidad de la moneda y el normal funcionamiento de los pagos internos y externos y, en general, efectuar operaciones con instituciones financieras públicas o privadas". 
16. Más adelante, sobre la misma materia en el boletín aludido, se apuntó, "En relación con esta disposición, el representante del Ejecutivo explicó que sólo se le entregaba la acción penal al Consejo de Defensa del Estado en consideración a la complejidad y gravedad del delito que se investiga, teniendo en cuenta que las denuncias deben estar cabalmente fundamentadas en base a los antecedentes recogidos en la investigación administrativa preliminar, evitándose, con esto, que se pudieran producir acusaciones irresponsables que en definitiva perjudicaran a inversionistas serios y responsables".

17. Sobre lo expresado en el párrafo precedente, nos permitimos transcribir parte de la sesión № 17 del Senado, en la que se trató este aspecto, que dice: "Continuaron expresando que, dada la complejidad de este delito, los Estados deben actuar con equipos multidisciplinarios, razón por lo cual no resulta oportuno que un tribunal, frente a cualquier denuncia que realice un particular, inicie una actuación que puede no tener éxito. Por otra parte, si bien es cierto resulta indispensable establecer, como Estado y como sistema económico, una sanción para el denominado "lavado de dinero", ello no puede permitir que la figura penal se preste para finalidades distintas, como desprestigiar a otras personas mediante una simple denuncia sin mayores fundamentos.

Ello, destacaron, justifica la existencia de una investigación preliminar como la que se propone en la iniciativa, en una fórmula que busca equilibrar, por una parte, la penalización de esta conducta, y por otra, proteger y salvaguardar a la mayoría, que son los legítimos inversionistas, tanto nacionales como extranjeros.

En consideración a estos antecedentes, se reservó, en primer lugar, el ejercicio de la acción penal a un organismo responsable, de forma tal que fuera ejercida luego de concluir una investigación integral con los recursos necesarios para poder comprobar la efectividad del hecho delictivo y, eventualmente, la participación".

18. Según el artículo 14 de la Ley de Drogas, dicho Consejo recibe las denuncias e informaciones pertinentes de terceros, y con el quórum de los dos tercios de sus miembros en ejercicio, ordenará investigar los hechos, la que tiene un carácter no contencioso, y obligatorio sólo respecto de los funcionarios, y de las entidades a que se refiere el inciso $1^{\circ}$ y $2^{\circ}$ del artículo 16 y letra d) del inciso $3^{\circ}$ del mismo artículo. Otra facultad, de acuerdo al artículo 15, es que puede imponerse de cualquier sumario penal y de otro proceso reservado o secreto en que se sospeche fundadamente la existencia de antecedentes acerca del delito de lavado de dinero. Esta disposición viene a ratificar una prerrogativa del Consejo, que ya se establecía en la Ley Orgánica del Consejo de Defensa del Estado.

19. El artículo 16 de la misma Ley, señala varias de las atribuciones detalladas en forma minuciosa, que le corresponden al Consejo, algunas de ellas podrán ser requeridas directamente y otras por la vía judicial, por ejemplo, decretar órdenes de arraigo, incautación de documentos, etc. Una de las atribuciones fundamentales introducidas por la Ley 19.393 de 22 de junio de 1996, es el levantamiento del secreto bancario, "en la investigación del delito de lavado de dinero", medida que estaba contemplada en el anterior Proyecto, pero que fue rechazada por el Tribunal Constitucional, y que ahora está en la reciente modificación.

20. El artículo16, en sus letras a), b) y c), indican: 
"a) Impedir la salida del país de aquellas personas de quienes a lo menos, se sospeche fundadamente que están vinculadas a alguno de los hechos previstos en el artículo 12 de esta ley, por un período máximo de sesenta días. Para estos efectos, deberá comunicar la prohibición o su alzamiento a la Policía de Investigaciones y a Carabineros de Chile. En todo caso, transcurrido este plazo, la medida de arraigo caducará por el solo ministerio de la ley, de lo cual deberán tomar nota de oficio los organismos señalados;

b) Ordenar alguna de las medidas a que se refiere el artículo 19 por un plazo no superior a sesenta días;

c) Recoger e incautar la documentación y los antecedentes probatorios necesarios para la investigación de los hechos, en caso de aparecer indicios graves que de esta diligencia hayan de resultar el descubrimiento o la comprobación de algún hecho o circunstancia importante para aquélla.

Esta medida sólo podrá ser encomendada a un abogado funcionario del Consejo de Defensa del Estado, el cual levantará acta de ella, la que expresará el lugar donde se practica, el nombre de las personas que intervengan, los incidentes ocurridos, la hora en que hubiere principiado y aquella en que concluyere, la relación del registro en el mismo orden en que se hubiere efectuado y un inventario de los objetos que se recojan. Se entregarán copia de dicha acta y de la respectiva resolución, con indicación del tribunal que la dictó, a la persona de quien se ha recogido o incautado la documentación;".

21. El artículo 16 letra d), anota "Requerir la entrega de antecedentes o copias de documentos sobre cuentas corrientes bancarias, depósitos u otras operaciones sujetas a secreto o reserva, de personas naturales o jurídicas, o de comunidades, que sean objeto de la investigación, debiendo los bancos, otras entidades y personas naturales que estén autorizadas o facultadas para operar en los mercados financiero, de valores o seguros y cambiario, proporcionarlos en el más breve plazo".

22. Esta facultad es sumamente importante, pues este secreto o intimidad bancaria que se mantenía en nuestro país, en las cuentas corrientes bancarias, entrababa e impedía las investigaciones pertinentes sobre el origen ilícito de los beneficios o dineros que se depositan o llegan de una u otra forma a los bancos, pudiendo en algunos casos éstos provenir del lavado de dinero. La modificación no sólo se refiere a los bancos sino que a otras entidades, personas naturales o jurídicas que están autorizadas o facultadas para operar en los mercados financieros de valores, seguros y cambiarios. De acuerdo con la doctrina penal, y a los casos investigados principalmente en el extranjero estos delitos se cometían y se cometen por medio o a través de los bancos, instituciones financieras, casas de cambio, bolsas de valores, etc.

23. El artículo $1^{\circ}$ de la Ley sobre cuentas corrientes bancarias y cheques, D.F.L. $N^{\circ} 707$ del año 1982, del Ministerio de Justicia, publicado en el D.O. de 7 de octubre del mismo año, fijó el texto refundido, coordinado y sistematizado de la Ley, reza "La cuenta corriente bancaria es un contrato a virtud del cual un Banco se obliga a cumplir las órdenes de pago de otra persona hasta concurrencia de las cantidades de dinero que hubiere depositado en ella o el crédito que se haya estipulado.

El banco deberá mantener en estricta reserva, respecto de terceros, el movimiento de la cuenta corriente y sus saldos, y sólo podrá proporcionar estas informaciones, al librador o a quien éste haya facultado expresamente. 
No obstante, los Tribunales de Justicia podrán ordenar la exhibición de determinadas partidas de la cuenta corriente en causas civiles y criminales seguidas con el librador".

\section{Conviene recordar al respecto lo que el Mensaje de la Ley manifestaba:}

"Convencido de la complejidad y multiplicidad de las acciones que se desarrollan para ocultar tal origen ilícito, se ha contemplado una instancia de investigación preliminar, esencialmente administrativa y no contenciosa, a cargo de un organismo autónomo y especializado, como es el Banco Central de Chile - que ha sido sustituido en el primer trámite constitucional por el Consejo de Defensa del Estado -, el que deberá investigar y establecer, antes del inicio del proceso penal, la existencia de hechos sospechosos de tales conductas y recopilar pruebas que permitan fundamentar una acción penal. Durante esta investigación previa, entre otras facultades, dicho organismo queda autorizado, para imponerse del movimiento de determinadas cuentas corrientes bancarias, depósitos y otras operaciones sujetas por la ley a secreto o reserva, pertenecientes a personas naturales o jurídicas vinculadas a los hechos objeto de esta investigación.

El alzamiento del secreto bancario durante la investigación preliminar constituye una necesidad, sostiene el Mensaje, para poder establecer la efectividad de las transacciones ilícitas. Resulta esencial, por lo tanto, acceder a ella en esta etapa previa, a fin de determinar y ubicar los recursos antes de una precipitada transferencia de los mismos. En todo caso, y atendida la trascendencia de esta facultad, el proyecto contiene disposiciones que tienen por objeto adoptar el máximo de resguardos en esta etapa".

25. Sobre la forma o procedimiento de la diligencia para el levantamiento del secreto bancario y para la recolección de antecedentes, se dispone que tiene que hacerse solamente por la vía judicial, de la manera que ordena el propio artículo 16 letra d). Esto es, "Corresponderá al Ministro de la Corte de Apelaciones de Santiago, que el Presidente de Dicha Corte designe por sorteo, en el acto de hacerse el requerimiento, autorizar previamente la práctica de las diligencias a que se refiere el inciso precedente. El Ministro resolverá de inmediato, sin audiencia ni intervención de terceros. La resolución que rechace la práctica de las diligencias solicitadas, será someramente fundada y el Consejo de Defensa del Estado podrá apelar de ella. La apelación será conocida en cuenta y sin más trámite por la Sala de Cuenta, de la Corte de Apelaciones de Santiago, tan pronto se reciban los antecedentes". Más adelante se agrega: "El expediente se tramitará en forma secreta y será devuelto íntegramente al Consejo de Defensa del Estado, fallado que sea el recurso. Las resoluciones a que se refiere el inciso tercero se cumplirán desde que sean dictadas, sin necesidad de notificación alguna, háyase o no interpuesto recurso en su contra. El afectado tendrá derecho a apelar dentro de los cinco días siguientes a la fecha en que haya tomado conocimiento de ella. Tratándose de la medida establecida en la letra c), dicho plazo correrá desde que se le entregue el acta y la copia de la resolución a que se refiere dicha norma. La apelación se conocerá y fallará de la misma forma establecida en el inciso precedente.

Para llevar a efecto las actuaciones a que se refiere el inciso tercero de este artículo, autorizadas judicialmente, el Consejo de Defensa del Estado podrá recurrir al auxilio de la fuerza pública, la que será concedida por el Jefe de Carabineros o de la Policía de Investigaciones más inmediato sin más trámite que la exhibición de la autorización judicial correspondiente. La fuerza pública se entenderá facultada, en estos casos, para descerrajar y allanar si fuere necesario. 
Los notarios, conservadores y archiveros deberán entregar al Consejo de Defensa del estado, en forma expedita y rápida, los informes, documentos, copias de instrumentos y datos que se les soliciten.

El otorgamiento de cualquier antecedente mencionado en este artículo será gratuito y libre de toda clase de derechos e impuestos".

26. Estimamos que la medida referida, esto es, la autorización para que el Consejo tenga conocimiento del movimiento bancario y que corresponde en la actualidad al Ministro de la Corte de Apelaciones de Santiago, por razones de rapidez y de expedición, podría ser otorgado por el Ministro de la Corte de Apelaciones o por un Juez del Crimen, correspondiente al del lugar del funcionamiento del Consejo de Defensa del Estado, a cargo de la investigación ya referida, y que es el que puede solicitar este trámite.

27. Una vez terminada la investigación preliminar, la que es secreta, el Consejo con el voto favorable de los dos tercios de sus miembros en ejercicio, debe resolver según el artículo 18, si deduce o no la acción penal. Si no se hiciese, se ordena el archivo de los antecedentes, los que son secretos. Dicho artículo 18 prescribe "Concluida la investigación preliminar a que se refieren los artículos anteriores, el Consejo de Defensa del Estado, con el voto favorable de los dos tercios de sus miembros en ejercicio, resolverá acerca de la procedencia de deducir la acción penal. En caso contrario, ordenará el archivo de los antecedentes, los que permanecerán bajo la custodia del Secretario del Consejo con carácter secreto, sin perjuicio de la devolución de aquellos que fueren procedentes".

28. Impetrada la acción penal, el Juez del Crimen pertinente, debe adoptar las medidas que se especifican en el artículo 19, siguiéndose con la investigación sumarial correspondiente hasta la dictación de la sentencia del caso. Dicho precepto a la letra dispone "Deducida la acción penal por alguno de los delitos contemplados en el artículo 12, el Juez del Crimen adoptará todas las medidas necesarias para evitar el uso, aprovechamiento, beneficio o destino de cualesquiera clase de bienes, valores o dineros provenientes de los delitos materia del proceso. Para estos efectos, y sin perjuicio de las demás facultades conferidas por la ley, podrá decretar, entre otras, la prohibición de celebrar determinados actos y contratos y su inscripción en toda clase de registros, retener en bancos o entidades financieras depósitos de cualesquiera naturaleza que sean, impedir transacciones de acciones, bonos o debentures y en general, cuanto conduzca a evitar la conversión del proyecto ilícito en actividades que oculten o disimulen su origen delictual.

Sin perjuicio de prueba en contrario, se presumirá el origen ilícito de los bienes a que se refiere el inciso anterior". 
Revista de Derecho - Universidad Católica del Norte - Sede Coquimbo - 1998

\section{CARACTERISTICAS DEL DELITO DE LAVADO DE DINERO.}

Seguidamente trataremos las características generales del delito de lavado de dinero que como se ha venido repitiendo se tipifica y penaliza en el artículo 12 de la Ley 19.366 .

1. Delito Material: Conforme a la propia redacción del artículo 12, al referirse el legislador "que determinados bienes, valores, dineros, utilidad, provecho o beneficio, se han obtenido o provienen de la perpetración, en Chile o en el extranjero, de hechos constitutivos de algunos de los delitos contemplados en esta Ley", el delito de lavado de dinero puede clasificarse como material o de resultado, toda vez que se obtienen evidentes utilidades, ventajas y beneficios económicos con el tráfico ilícito de drogas.

2. En cuanto al iter criminis. Según el artículo 24 de la Ley, en la parte primera, y lo que es aplicable al lavado de dinero consigna: "Los delitos de que trata esta ley se sancionarán como consumados desde que haya principio de ejecución". En otras palabras, se produce lo que se llama en doctrina penal, la consumación anticipada del delito, cuando el autor se encuentra en la etapa externa de los actos de ejecución del delito. Hay una equiparación entre el principio de ejecución y la consumación o perfeccionamiento del delito. Se produce un problema que el legislador no definió lo que debe entenderse por principio de ejecución en la Ley de Drogas, y podría estarse a lo que preceptúa el artículo 7 del Código Penal, al definir la tentativa en su inciso $2^{\circ}$, esto es, cuando "el culpable da principio a la ejecución del crimen o simple delito, por hechos directos, pero falta uno o más para su complemento".

De acuerdo a la historia de la Ley esta disposición no es nueva y ya existía en la Ley 17.934. En la anterior Ley 18.403 derogada por la 19.366 , cuando el delito se encontraba en tentativa se facultaba al Tribunal para que rebajase la pena en uno o dos grados.

En el mismo artículo 24, se penaliza la conspiración al expresar "La conspiración para cometerlos será penado con presidio menor en su grado medio y multa de cuarenta a doscientas unidades tributarias mensuales". Recordemos que de acuerdo al artículo $8^{\circ}$ del Código Penal, "La conspiración y la proposición para cometer un crimen o simple delito, sólo son punibles en los casos en que la ley las pene especialmente". En el citado artículo $8^{\circ}$, se define lo que debe entenderse por conspiración al indicar "existe cuando dos o más personas se concertan para la ejecución del crimen o simple delito".

Conviene tener presente y de acuerdo al artículo 24 de la Ley 19.366, la conspiración para cometer los delitos de la Ley de drogas, y lo que es aplicable al lavado de dinero cuando se encuentra en la etapa de conspiración. Atento a la doctrina penal, varios autores consideran la conspiración como una de las etapas o fases del iter criminis, en que ya hay una manifestación de la voluntad criminal para cometer un delito, se ponen de acuerdo para su ejecución. Es una etapa más avanzada de los actos preparatorios pero menos desarrollada que los actos de ejecución.

3. En cuanto al atenuante de responsabilidad penal del artículo $11 \mathrm{~N}^{\circ} 7$ del Código Penal. Sobre este punto el artículo 32 precisa: "En los delitos contemplados en esta Ley no procederá la atenuante de responsabilidad penal contenida en el artículo 11 , Nº del Código Penal". Por su parte el artículo 11, del Código Penal, especifica "son 
circunstancias atenuantes", $N^{\circ} 7$ "se ha procurado con celo reparar el mal causado o impedir sus ulteriores perniciosas consecuencias".

De consiguiente en los delitos tipificados en la Ley de Drogas, y por lo tanto el delito de lavado de dinero, no se acepta esta atenuante, que en el fondo se materializa por regla general en la consignación de fondos por parte del procesado en la causa respectiva que se sigue en su contra. Antes de la Ley 19.366, existían una serie de fallos, y entre estos de la Corte Suprema, que dictaminaban la procedencia del atenuante, al estimarse que era de aplicación general. En los últimos años varias sentencias estaban por rechazar tal atenuante, toda vez que el bien jurídico tutelado, lo era la salud pública o la salud colectiva, y no era posible que con dineros se pretendiese reparar el mal causado.

Frente al lavado de dinero no rige al artículo $11 \mathrm{~N}^{\circ} 7$ del Código Penal, según la disposición expresa del artículo 32 de la ley en estudio, pues también se considera que el bien afectado por el lavado de dinero compromete entre otros bienes jurídicos la salud pública, los intereses del estado, la estabilidad financiera, etc.

4. Las circunstancias atenuantes del artículo 33 de la Ley 19.366 , esto es, la cooperación eficaz. Esta atenuante de la cooperación eficaz es una de las innovaciones de la Ley de Drogas, y está vinculada igualmente al lavado de dinero, y tiene completa vigencia.

El artículo 33 de la Ley 19.366, señala, en la primera parte, que la cooperación eficaz es una atenuante de responsabilidad criminal, al estipular: "Será circunstancia atenuante de responsabilidad penal la cooperación eficaz con la autoridad administrativa, policial o judicial, que conduzca a la determinación del cuerpo del delito o de sus autores, cómplices o encubridores, o sirva para prevenir o impedir la perpetración o consumación de otros delitos de igual o mayor gravedad contemplados en esta Ley. En estos casos, el tribunal podrá reducir la pena hasta en dos grados".

Esta nueva circunstancia atenuante se ha estimado necesaria para la investigación del delito, para determinar el cuerpo del delito, quienes son los partícipes del mismo o impedir la perpetración o consumación de otros delitos, el efecto es facultativo para el Tribunal y puede rebajar la pena hasta en dos grados.

De acuerdo con la Ley, no todo acto de cooperación puede ser calificado de eficaz y disminuir la pena, y es así como la propia ley calificó lo que debe entenderse por cooperación eficaz, al expresar "Se entiende por cooperación eficaz el suministro de datos o informaciones precisos, verídicos y comprobables, que contribuyan necesariamente al esclarecimiento aludido".

5.En cuanto a la reincidencia. El artículo 35 de la Ley en examen reza: "Para determinar si existe reincidencia respecto de los delitos castigados por esta Ley, se tendrán también en cuenta la sentencias firmes dictadas en el extranjero, aun cuando la pena impuesta no haya sido cumplida". Este precepto está indicando que para los efectos de la reincidencia en delitos contemplados en la Ley de Drogas, se considerarán las sentencias judiciales condenatorias dictadas en otro país, no obstante que la pena no haya sido cumplida, sobre la materia. Por lo tanto, tiene el efecto de agravar la pena, cuando el delincuente tenga pendiente el plazo de la sentencia, o lo haya completado. También podría aplicarse la reincidencia genérica y la específica según el artículo 12 $N^{\circ} 14$ y 15 del C.P., por no estar excluído en esta Ley. 
6. En cuanto a la extradición. La parte final del artículo 35 agrega: "Asimismo, estos delitos serán susceptibles de extradición, tanto activa como pasiva, aun en ausencia de reciprocidad o de tratado sobre la materia". Creemos que esta parte es importante y también aclaratoria en orden a que los delitos de la Ley de Drogas son extraditables, tanto cuando un país la pide o se la solicitan, en ausencia de reciprocidad o de la existencia de tratados. Estos aspectos están confirmando el carácter que se le asigna a los delitos de tráfico de drogas ilegales, de tratarse de delitos internacionales, dentro del Derecho Penal Internacional.

7. En cuanto a su fallo. El artículo 36 dispone: "En la sustanciación y fallo de los procesos por los delitos a que se refiere esta ley, los tribunales apreciarán la prueba de acuerdo con las reglas de la sana crítica". Al respecto se dejó constancia en las sesiones de la Cámara de Diputados, que "esta disposición ha sustituído la apreciación de la prueba en conciencia por la que aparece señalada en esta norma que, de acuerdo a la doctrina, sería más exacta. Bastaría que el juez aprecie una sola prueba legal para que en base a ella se forme la convicción ya sea para condenar o absolver".

Este precepto le da una amplia facultad al Tribunal para que pueda según las probanzas de autos, formarse la convicción de que se ha cometido o no el delito de lavado de dinero y quienes son los responsables de acuerdo a su experiencia y a la lógica.

8. La improcedencia de ciertas medidas contempladas en la Ley 18.216. El artículo 40 añade: "No procederán las medidas alternativas de reclusión nocturna y libertad vigilada contempladas en los artículos 8 y 15 de la Ley $N^{\circ} 18.216$ respecto de condenados por delitos previstos en esta ley, a menos que les hubiere sido reconocida la circunstancia atenuante establecida en el artículo 33". Por expresa disposición de la Ley, no se aplican estos beneficios, considerando la gravedad de los delitos sancionados en la Ley de Drogas, con la excepción que regirán cuando el Tribunal considere que al condenado le beneficie la atenuatoria de la cooperación eficaz.

\section{FORMA DE OPERAR EN GENERAL EL LAVADO DE DINERO.}

Sin perjuicio de las diversas acciones ilegales que forman estructuralmente el lavado de dinero, en el artículo 12, de la Ley 19.366, ya examinada, recordemos que el lavador o blanqueador es una persona natural y los distintos autores $u$ organismos existentes han señalado varias formas operativas.

1. "Según los especialistas del FOPAC (sigla correspondiente" Fondos procedentes de las Actividades Criminales) -INTERPOL, el modus operandi del encubrimiento financiero se materializa, generalmente, a través de las siguientes actividades:

A) Compra de bienes de consumo como automóviles, casas, joyas, obras de arte, etc.

B) Exportar de modo subrepticio e ilegal el dinero mal habido y depositarlo en cuentas cifradas en el extranjero; o abrir empresas de intercambio de divisas, de exportación, etc.

C) Convertir las divisas obtenidas, a través de organización financieras locales, en medios de pagos cómodos, como los bonos de caja, cheques de gerencia, cheques de viajero o las cuentas corrientes múltiples". (Prado, ob. cit., pág. 16) 
2. Por su parte Diego J. Gómez Iniesta, en un artículo publicado en la Revista de Estudios de Derecho Penal Económico, titulado "Medidas Internacionales contra el Blanqueo de Dinero y su Reflejo en el Derecho Español", ediciones de la Universidad de Castilla-La Mancha, 1994, págs. 139 y 140, agrupa las formas de actuación en dos grandes categorías:

a) Operaciones en las que interviene una entidad bancaria:

- Operaciones de depósito de dinero que se fracciona en pequeños importes, eludiendo la posible norma que imponga obligaciones de identificación del operador u obligación de revelación de los datos de la operación, seguido de una conversión por medio de la adquisición de instrumentos de pago o de valores mobiliarios efectuados a través de entidades de crédito, intermediarios financieros, agencias de cambio y bolsa, etc.

- Anotaciones bancarias de depósitos de cantidades relativamente pequeñas con diferentes nombres, en diferentes entidades bancarias, en diferentes ciudades que a través de transacciones electrónicas se envían a otras cuentas de otros bancos nacionales o extranjeros.

- Apertura de las llamadas cuentas innominadas o cuentas secretas cuya titularidad pertenece al banco por razones de tesorería, técnicas, etc., para realizar operaciones "de un día" y a través de las cuales se introducen fondos ajenos lo cual proporciona un alto nivel de anonimato.

- Certificados de depósito que movilizan las imposiciones a plazo fijo, transacciones con base en letras de cambio y pagarés, los seguros de prima única, etc.

b) Operaciones en las que interviene necesariamente una entidad bancaria:

- Adquisición de metales y piedras preciosas, obras de arte, etc.

- Financiación de empresas que por su naturaleza están muy necesitadas de liquidez o una constante disponibilidad de dinero en efectivo como las compañías de seguro. dad.

- Adquisición de bienes inmuebles y muebles de gran valor y fácil comerciabili-

- Inversión del capital procedente de un acto ilícito en empresas ubicadas en países considerados como paraísos jurídicos y fiscales (Hong-Kong, Bahamas, Kuwait, Panamá, etc.) que permite que dichos capitales sean blanqueados antes de llegar a los países más desarrollados.

- Concesión de créditos por parte de las organizaciones criminales o sus agentes en condiciones más favorables que las dadas por una entidad de crédito a una empresa en crisis con el fin de obtener su control". 